\title{
KEANEKARAGAMAN DAN KEMELIMPAHAN KUPU-KUPU DI KAWASAN WISATA AIR TERJUN IRENGGOLO KEDIRI
}

\author{
Tutut Indah Sulistiyowati ${ }^{1)}$ dan Ida Rahmawati ${ }^{2)}$ \\ Universitas Nusantara PGRI Kediri \\ Email: tututindah.team@gmail.com
}

\begin{abstract}
ABSTRAK
Telah dilakukan penelitian mengenai keragaman kupu-kupu di kawasan Wisata Air Terjun Irenggolo Kediri pada bulan Februari hingga Juli 2018. Penelitian ini bertujuan untuk mendapatkan database tentang keragaman dan kelimpahan kupu-kupu di kawasan Wisata ini. Metode yang digunakan untuk mengkoleksi kupu-kupu adalah dengan metode VES. Kupu ditangkap menggunakan jaring serangga dan dikoleksi menggunakan kertas papylote. Semua spesies diidentifikasi di laboratorium zoology dan dikonsultasikan pada ahli. Data keragaman kupu dianalisis menggunakan indeks Shanon Winner. Hasil penelitian ini menunjukkan sebanyak 35 spesies kupu dengan total jumlah 1.622 individu. Berdasarkan analisis kuantitatif, disimpulkan bahwa meskipun kekayaan individu tinggi, namun derajad kemelimpahan masing-masing spesies rendah. Adapun spesies yang derajad kelimpahannya cukup adalah Hasora taminatus $(14,5)$ dan Chilades pandava $(16,5)$. Untuk menjaga kelestarian jenis kupu dan menjaga kemelimpahannya, perlu dilakukan edukasi kepada pengunjung agar tetap menjaga keberadaan tumbuhan liar di kawasan wisata Air Terjun Irenggolo Kediri.
\end{abstract}

Kata kunci: Keanekaragaman kupu, media belajar

\section{PENDAHULUAN}

Air terjun Irenggolo Kediri telah dijadikan sebagai tempat penelitian beraneka cabang ilmu, paku (Rizky, 2016), reptil dan aphibi (Jamaludin et.al, 2016), inventarisasi kupu-kupu (Sa'diyah dan Sulistiyowati, 2016), capung (Prameswari dan Sulistiyowati, 2016), dan masih banyak bidang yang lainnya. Kupu-kupu menjadi penting karena memiliki jasa ekologis yang banyak, diantaranya sebagai pollinator (Ahmad, 2002) dan indikator kualitas lingkungan (Fermon, 2002; Yamamtono et.al, 2007; dan Rahayuningsih et.al, 2012). Sedangkan dari segi estetika, kupu-kupu memiliki sayap tertutup sisik dengan warna yang kompleks dan indah (Mastrigt dan Rosariyanto, 2005). Dari segi komersial, telah banyak kupu yang dibudidayakan untuk dijual baik produk sampingannya (contoh: ulat sutra) (Nurjayanti, 2011) ataupun kupu itu sendiri untuk dijadikan souvenir (Gustami dan Waluyo, 2002).

Keragaman kupu pada suatu tempat dapat dijadikan sebagai indikator bahwa tempat tersebut masih belum tercemar (Rahayuningsih et.al, 2012). Diketahui bahwa kupu memiliki toleransi habitat yang sempit, sehingga apabila habitat kupu telah tercemar, maka cara kupu beradaptasi adalah dengan memimik 
warna lingkungan, atau berpindah tempat (Resh dan Carde, 2003; Molles, 2013). Berbagai bentuk adaptasi kupu bergantung pada kemampuan masing-masing jenis dalam bertahan hidup.

$$
\text { Penelitian }
$$

tentang

keragaman kupu di kawasan wisata Irenggolo Kediri pernah dilaporkan oleh Sa'diyah dan Sulistiyowati (2016), namun hasil penelitian ini hanya mencakup sebagian kecil lokasi Irenggolo. Maka perlu diadakan penelitian menyeluruh dan komplek untuk mengetahui keragaman kupu yang terdapat di kawasan wisata Air Terjun Irenggolo Kediri.

\section{METODE}

Penelitian ini dilakukan selama enam bulan, dimulai pada bulan Februari hingga Juli 2018. Pengamatan di lapangan terbagi dalam enam plot pengamatan, yaitu: taman dekat kolam hingga kebun sayur (1), jalan setapak menuju air terjun (2), taman dekat air terjun hingga tepian sungai (3), semak batas antara warung dengan perkebunan (4), area perkemahan (5), dan semak sebrang sungai menuju hutan (6) (Gambar 1).

Pengamatan kupu dilakukan pada dua kurun waktu, yaitu pagi (pukul 06.00 - 13.00) dan sore (pukul 13 - 17.00) menggunakan metode VES. Kupu-kupu ditangkap menggunakan jaring serangga, dan dikoleksi pada botol koleksi. Semua kupu yang tertangkap diidentifikasi di laboratorium Zoologi Universitas Nusantara PGRI Kediri, dan divalidasi oleh ahli. Kupu-kupu diidentifikasi dengan menggunakan berbagai panduan (Peggie dan Amir, 2006; Peggie, 2011; Syamsudin, 2011; dan Peggie, 2014). Kupu yang telah teridentifikasi dilepas kembali, namun kupu yang mewakili masingmasing spesies diawetkan dan dijadikan media belajar.

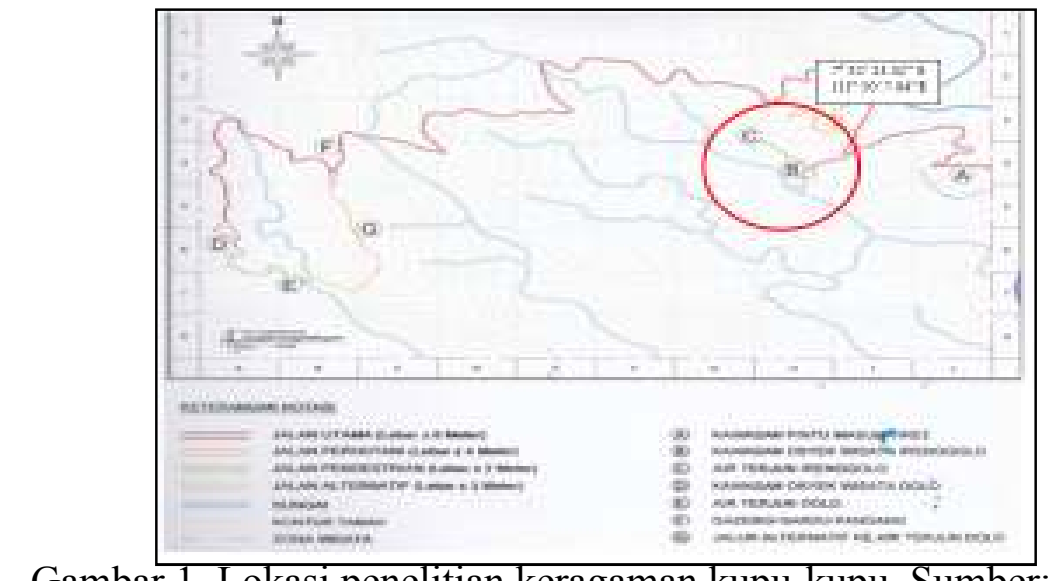

Gambar 1. Lokasi penelitian keragaman kupu-kupu. Sumber: Dinas

Pariwisata dan Kebudayaan Kabupaten Kediri (2016) 
Indeks keanekaragaman jenis kupu dihitung menurut indeks ShanonWiener $\left(\mathrm{H}^{\prime}\right)$ :

keterangan:

$$
H^{\prime}=-\sum p i \operatorname{Ln} p i
$$

Pi: perbandingan jumlah individu suatu jenis dari keseluruhan jenis yang ditemukan. (pi= $\mathrm{ni} / \mathrm{N})$

ni: jumlah total individu spesies ke $\mathrm{i}$

$\mathrm{N}$ : jumlah total individu seluruh spesies yang ditemukan

$\mathrm{H}$ : indeksShannon-Wiener

Dengan ketentuan:

Jika nilai $\mathrm{H}<1$ : keanekaragaman sangat rendah.

Jika nilai $1<\mathrm{H}<1,5$ : keanekaragaman rendah.

Jika nilai $1,5<\mathrm{H}<2$ : keanekaragaman sedang.

Jika nilai $\mathrm{H}>2$ : keanekaragaman tinggi.

Indeks kemerataan jenis pada lokasi penelitian dihitung berdasarkan indeks kemerataan Simpson sebagai berikut:

$$
E=\frac{H^{\prime}}{\operatorname{Ln} S}
$$

Keterangan:

H': indeks keanekaragama Shannon - Wiener

E: indekskemerataanjenis

S: jumlah total spesies yang ditemukan

Dengan ketentuan jika nilai E mendekati 1, menunjukan jumlah individu antar jenis relatif sama/ merata.
Pengukuran

derajat kemelimpahan relatif kupu-kupu yang dijumpai dalam penelitian dikategorikan dalam 4 kelompok menurut Buden (2000) yaitu: dikatakan banyak dijumpai (Ba) jika minimal tercatat 30 perjumpaan/hari, dikatakan cukup banyak $(\mathrm{Cu})$ jika dijumpai 10-30 perjumpaan/hari, kategori jarang dijumpai (Ja) jika hanya 10 perjumpaan/hari, dan kategori langka (La) jika hanya terdapat dibawah 5 perjumpaan/hari pada sebagian besar waktu survei.

\section{HASIL DAN PEMBAHASAN}

Suhu dan kelembaban udara yang tercatat selama pengamatan adalah $21 \pm 2{ }^{\circ} \mathrm{C}$ dan $68 \pm 2 \%$. Pada suhu hangat $\left(21-22^{0} \mathrm{C}\right)$, kupu-kupu beraktifitas merentangkan sayap untuk menghangatkan tubuh. Pada suhu ini, kupu-kupu banyak bertengger di dedaunan perdu dan semak, atau hanya hinggap begitu saja di lahan-lahan terbuka yang terkena sinar matahari.

Sebanyak 1.622 individu kupu telah teramati. Secara keseluruhan terdapat sebanyak lima famili dan 35 spesies kupu (Tabel 1). Kelima famili tersebut yaitu Nymphalidae, Pieridae, Papilionidae, Lycaenidae, dan Hesperidae. Spesies yang paling banyak dijumpai adalah pada famili Nymphalidae, sedangkan yang paling sedikit adalah spesies dari Hesperidae. Tumbuhan pakan Hesperidae adalah anekajenis Zingiberaceae (Peggy, 2006). Pada plot pengamatan, suku tumbuhan ini 
tidak terdapat banyak. Hal inilah salah satu penyebab sedikitnya perjumpaan Hesperidae.

Kupu-kupu yang paling sering dijumpai adalah Chilades pandava, yaitu sebanyak 165 individu dengan rata-rata 16 kali perjumpaan dalam setiap pengamatan dalam keseluruhan plot. Sedangkan yang paling jarang dijumpai yaitu Troides criton. Dari 10 kali pengamatan, hanya dijumpai sebanyak enam individu $T$. criton. Berdasarkan hasil pengamatan,
T.criton hanya ditemukan pada satu lokasi dari enam plot pengamatan, yaitu plot ke-enam. Tidak ditemukan T.criton yang hinggap pada tumbuhan atau substrat lain. T.criton ditemukan selalu dalam keadaan terbang. Hingga artikel ini dipublikasi, belum ditemukan tumbuhan inang atau pakan dari T.criton dalam area pengamatan. Dengan demikian, berdasarkan Budden T.criton dengan beberapa spesies lain ditempatkan pada kategori langka untuk dijumpai.

Tabel 1. Hasil pengamatan kupu-kupu pada enam plot pengamatan: jumlah individu, keragaman, kemerataan, dan derajad kemelimpahan

\begin{tabular}{clccc}
\hline Famili & Sspesies & $\begin{array}{c}\text { Jumlah } \\
\text { individu }\end{array}$ & $\begin{array}{c}\text { Rata-rata } \\
\text { perjumpaan }\end{array}$ & $\begin{array}{c}\text { Derajad } \\
\text { kemelimpahan }\end{array}$ \\
\hline Nymphalidae & Elymnias nesaea & 25 & 2,50 & $\mathrm{La}$ \\
& Elymnias & & & \\
& hypermnestra & 19 & 1,90 & $\mathrm{La}$ \\
& Juninia atlites & 27 & 2,70 & $\mathrm{La}$ \\
& Hypolimnas bolina & 93 & 9,30 & $\mathrm{Ja}$ \\
Doleschallia & & & \\
bisaltide & 16 & 1,60 & $\mathrm{La}$ \\
& Junonia almana & 25 & 2,50 & $\mathrm{La}$ \\
& Danaus chrisippus & 15 & 1,50 & $\mathrm{La}$ \\
& Euploea mulciber & 52 & 5,20 & $\mathrm{Ja}$ \\
& Cupha erymanthis & 22 & 2,20 & $\mathrm{La}$ \\
& Idiopsis juventa & 21 & 2,10 & $\mathrm{La}$ \\
Neptis hylas & 48 & 4,80 & $\mathrm{La}$ \\
& Yphtima philomela & 92 & 9,20 & $\mathrm{Ja}$ \\
& Ariadne ariadne & 37 & 3,70 & $\mathrm{La}$ \\
Euploea phaenareta & 35 & 3,50 & $\mathrm{La}$ \\
\hline Pieridae & Appias olferna & 56 & 5,60 & $\mathrm{Ja}$ \\
& Eurema blanda & 74 & 7,40 & $\mathrm{Ja}$ \\
Delias hyparete & 34 & 3,40 & $\mathrm{La}$ \\
Delias periboea & 39 & 3,90 & $\mathrm{La}$ \\
Catopsila scylla & 77 & 7,70 & $\mathrm{Ja}$ \\
& & &
\end{tabular}




\begin{tabular}{|c|c|c|c|c|}
\hline & Eurema hecabe & 69 & 6,90 & $\mathrm{Ja}$ \\
\hline & Catopsila pamona & 44 & 4,40 & $\mathrm{La}$ \\
\hline & Eurema sari & 69 & 6,90 & $\mathrm{Ja}$ \\
\hline & Gandaca harina & 36 & 3,60 & $\mathrm{La}$ \\
\hline & Delias belisama & 40 & 4,00 & $\mathrm{La}$ \\
\hline & Cepora ludith & 26 & 2,60 & $\mathrm{La}$ \\
\hline \multirow[t]{6}{*}{ Papilionidae } & $\begin{array}{l}\text { Graphium } \\
\text { agamemnon }\end{array}$ & 39 & 3,90 & $\mathrm{La}$ \\
\hline & Papilio demoleus & 17 & 1,70 & $\mathrm{La}$ \\
\hline & Graphium doson & 16 & 1,60 & $\mathrm{La}$ \\
\hline & Papilio memnon & 46 & 4,60 & $\mathrm{La}$ \\
\hline & Papilio polytes & 15 & 1,50 & $\mathrm{La}$ \\
\hline & Troides criton & 6 & 0,60 & $\mathrm{La}$ \\
\hline \multirow[t]{3}{*}{ Lycaenidae } & Chilades pandava & 165 & 16,50 & $\mathrm{Cu}$ \\
\hline & Lampides boeticus & 28 & 2,80 & $\mathrm{La}$ \\
\hline & Jamides abdul & 54 & 5,40 & $\mathrm{Ja}$ \\
\hline Hesperidae & Hasora taminatus & 145 & 14,50 & $\mathrm{Cu}$ \\
\hline \multicolumn{2}{|c|}{ Jumlah Individu } & & 1.622 & \\
\hline \multicolumn{2}{|c|}{ Indeks Keanekaragaman } & & 3,32 & \\
\hline \multicolumn{2}{|c|}{ Indeks kemerataan } & & 0,09 & \\
\hline
\end{tabular}

*derajat kemelimpahan: $\mathbf{B a}=$ banyak jika minimal tercatat 30 perjumpaan/ hari, $\mathbf{C u}=$ cukup banyak jika 10-30 perjumpaan/ hari, $\mathbf{J a}=$ jarang jika hanya 5-10 perjumpaan/ hari dan $\mathbf{L a}=$ langka jika di bawah 5 perjumpaan/ hari pada periode sampling.

Jika dirunut berdasarkan perhitungan Budden, maka terdapat sebanyak 24 jenis kupu yang tergolong langka dijumpai, sembilan jenis jarang dijumpai, dan dua jenis yang cukup banyak untuk dijumpai (Tabel 1). Perhitungan Budden ini didasarkan pada seringnya suatu jenis dijumpai selama kurun pengambilan data. Sehingga, hasil perhitungan ini hanya berlaku pada suatu kawasan tertentu. Hal ini akan menghasilkan predikat yang berbeda untuk jenis yang sama pada tempat berbeda. Adapun jenis yang dilindungi menurut CITES adalah T.criton (Peggie, 2011).

Banyaknya individu kupu yang telah ditemukan dari beraneka jenis menyebabkan keanekaragaman kupu pada kawasan wisata air terjun Irenggolo Kediri tergolong tinggi $(3,32)$.

Tingginya keragaman kupu pada suatu tempat didukung oleh berbagai faktor, antara lain faktor biotik dan abiotik. Faktor biotik meliputi ketersediaan sumber pakan dan tumbuhan inang (Resh dan Carde, 2003). Telah diketahui bahwa famili tumbuhan Asteraceae, Poaceae, 
Melastomaceae, Verbencea, Athyriceae, Urticaceae, Araceae, Mimosaceae, dan Solanaceae merupakan tumbuhan pakan dari kupu-kupu famili Nymphalidae (Arrummaisha, 2014). Sehingga keberadaan berbagai jenis tumbuhan menentukan keragaman kupu. Faktor abiotik yang mempengaruhi keberadaan kupu pada suatu tempat adalah kelembapan, suhu, dan intensitas cahaya (Priyono dan Muhamad, 2013). Disebutkan bahwa kupu-kupu menghindari tempat dengan kelembapan tinggi hingga basah. Kupu akan meninggalkan telurnya pada tempat yang memungkinkan keberlangsungan keturunannya (Resh dan Carde, 2003). Sehingga kombinasi kedua faktor biotik dan abiotik menjadi penentu keberadaan kupu pada suatu tempat.

Berdasarkan perhitungan Simpson, diketahui bahwa indeks keragaman kupu pada wilayah ini tergolong rendah yaitu sebesar 0,09 . Artinya, terdapat dominasi jenis pada beberapa wilayah pengamatan. Sebagai contoh, dari hasil pengamatan diketahui bahwa pada pos pertama dijumpai hampir semua jenis kupu. Temuan mengenai dominasi habitat ini akan ditulis dalam artikel berikutnya.

\section{KESIMPULAN DAN SARAN Kesimpulan}

Keanekaragaman kupu pada kawasan wisata Irenggolo Kediri tergolong tinggi, maka keberadaan setiap jenis kupu perlu tetap dijaga dan bahkan ditambah. Hal sederhana yang perlu dilakukan adalah dengan membiarkan aneka tumbuhan tetap tumbuh dan terjaga dengan baik.

\section{Saran}

Lebih lanjut lagi, perlu memperkenalkan kekayaan jenis kupu pada setiap pengunjung dan pengelola.

\section{DAFTAR PUSTAKA}

Achmad A. 2002. Potensi dan sebaran kupu-kupu di Kawasan Taman Wisata Alam Bantimurung. Dalam: Workshop Pengelolaan Kupu-Kupu Berbasis Masyarakat. Bantimurung, 5 Juni 2002.

Arrummaisha, L.D. 2014. Preferensi Kupu-Kupu

Famili

Nymphalidae dan Lycaenidae pada Tumbuhan di Wisata Air Terjun Coban Rais Kota Batu, Jawa Timur.Skripsi. Fakultas MIPA UM

Fermon, H. 2002. The Butterfly Community of a Managed West African Rainforest: Patterns of Habitat Specificity, Diversity, Stratification and Movement. Dissertation. University of Gottingen, Gottingen, Germany.

Gustami., dan Waluyo, Heru. 2002. Valuasi Ekonomi Biodiversity Kars: Studi 
Kasus Valuasi Ekonomi Kawasan Kars Maros, Sulawesi Selatan. Manusia dan Lingkungan. Vol IX. No 2: $69-78$

Jamaludin, M.A., Pratama, M.Y.A., Pahlevi, M.I., Hanifa, B.F., dan Utami, B.U. 2016. Inventarisasi Amfibi dan Reptil di Wilayah Air Terjun Irenggolo Kediri. Prosiding Seminar Nasional Pendidikan dan Saintek 2016. Universitas Muhammadiyah Surakarta.

Molles, Manuel. 2013. Ecology Concepts and Applications: 198-200. Connect Learn Succed: New York

Nurjayanti, E.D. 2011. Budidaya Ulat Sutera dan Produksi Benang Sutera Melalui Sistem Kemitraan pada Pengusahaan Sutera Alam (PSA) Rengaloh Kabupaten Pati. Mediagro. Vol 7.No 2: 1-10

Peggie, Djuniati., dan Amir, Mohammad. 2006. Practical Guide ti the Butterflies of Bogor Botanic Garden: Panduan Praktis Kupu-kupu di Kebun Raya Bogor. LIPI. Jakarta.

Peggie, Djuniati. 2011. Precious and Protected Indonesian Butterflies: Kupu-kupu di Indonesia yang Bernilai dan Dilindungi. PT Binamitra Megawarna. Jakarta
Peggie, Djuniati. 2014. Mengenal Kupu-kupu. Pandu Aksara Publishing. Jakarta

Prameswari, I.T dan Sulistiyowati, T.I. 2016. Inventarisasi Capung (Odonata) di Kawasan Air Terjun Irenggolo Kediri Jawa Timur. Prosiding Seminar Nasional IV Hayati. Universitas Nusantara PGRI Kediri

Priyono B., dan Muhammad A. 2013. Keanekaragaman jenis kupu-kupu di Taman KEHATI UNNES. Biosaintifika 5 (2): 76-81. Rahayunungsih, M., Oqtafiana, R., dan Priyono. 2012. Keanekaragaman Kupukupu Superfamili Papilionidae di Dukuh Banyuwindu Desa Limbangan Kecamatan Limbangan Kabupaten Kendal. Jurnal MIPA: 35(1)

Resh, V.H., dan Carde, R.T. 2003. Encyclopedia of Insects: 660669. Academic Press: USA

Rizky, M.A. Inventarisasi Tumbuhan Paku (Pteridhophyta) di Kawasan Wisata Air Terjun Dholo, Kabupaten Kediri. Skripsi. Universitas Nusantara PGRI Kediri.

Sa'diyah, K dan Sulistiyowati, T.I. 2016. Inventarisasi KupuKupu (Lepidoptera diurnal) di Kawasan Wisata Air Terjun Irenggolo Kabupaten 
Kediri. Prosiding Seminar Yamamoto, N., Yokoyama, J., dan Nasional IV Hayati. Universitas Nusantara PGRI Kediri.

Syamsudin, TS. 2011. Mengenal Kupu-kupu Tangkuban Parahu dan Sekitarnya. Bina Budhaya. Bandung Kawata M. 2007. Relative resources abundance explains butterfly biodiversity in island communities. PNAS 104: 10524-10529. 